\title{
Diagnosis of electronics equipment companies in Rio Grande do Sul in terms of environmental
} impacts and reverse logistics system

Jaqueline Terezinha Martins Corrêa Rodrigues ${ }^{1}$, Instituto Federal de Educação, Ciência e Tecnologia do Rio Grande do Sul

Liane Werner ${ }^{2}$, Universidade Federal do Rio Grande do Sul, Instituto de Matemática e Estatística

\section{RESUMO}

\begin{abstract}
A Política Nacional dos Resíduos Sólidos (PNRS), aprovada em 2010, exige a implantação de sistemas de logística reversa para equipamentos eletroeletrônicos (EEE). O objetivo deste artigo é avaliar como as indústrias de EEE do Rio Grande do Sul (RS) estão agindo para reduzir o impacto ambiental de sua produção e como atendem a legislação ambiental no que se refere aos resíduos destes equipamentos. O estudo foi realizado com 19 indústrias de EEE situadas no RS, em 2015. O questionário, instrumento de coleta de dados, utilizou a escala Likert para avaliar as organizações em relação aos processos produtivos, produtos, informações aos consumidores e PNRS. Para análise dos dados utilizou-se as frequências absolutas, os coeficientes de correlação posto-ordem $\mathrm{r}_{\mathrm{s}}$ de Spearman e o índice geral $\mathrm{IG}_{\mathrm{k}}$. Pode-se ressaltar que as organizações participantes já realizam ações para minimizar o impacto de sua produção, mas ainda não realizam ações efetivas para alteração da composição dos produtos restringindo substâncias perigosas ou modificando o design para reciclabilidade. Além disso, o sistema de logística reversa não é realidade da maioria das organizações pesquisadas.
\end{abstract}

Palavras-chave: Equipamentos Eletroeletrônicos. EEE. Indústria. RS.

\section{ABSTRACT}

The National Solid Waste Policy (PNRS), approved in 2010, requires the implementation of reverse logistics systems for electrical and electronic equipment (EEE). The purpose of this article is to understand how the EEE industries of Rio Grande do Sul (RS) are acting to reduce the environmental impact of their production and how they comply with the environmental legislation regarding the waste of this equipment. The study was conducted with 19 EEE industries located in Rio Grande do Sul, in 2015. The questionnaire, a data collection instrument, used the Likert scale to evaluate organizations in relation to productive processes, products, information to consumers and PNRS. For data analysis, the absolute frequencies, the Spearman correlation coefficient and the general IGk index were used. It should be emphasized that the participating organizations already take actions to minimize their production impact, but still do not take effective measures to change the products' composition, restrict dangerous substances or modifyi the design for recyclability. In addition, the reverse logistics system is not the reality of most organizations surveyed.

Keywords: Electric and Electronic Equipment; EEE; Industry, RS.

1. Rua Dra. Maria Zélia Carneiro de Figueiredo, 870 - Bairro Igara III - CEP: 92412-240, Canoas/RS, jaquecorrea@yahoo.com.br; 2.werner.liane@gmail.com

RODRIGUES, J.T.M.C.; WERNER, L. Diagnóstico de indústrias de equipamentos eletroeletrônicos do Rio Grande do Sul em relação aos impactos ambientais e sistema de logística reversa. GEPROS. Gestão da Produção, Operações e Sistemas, v. 15, n. 1, p. $92-113,2020$.

DOI: $10.15675 /$ gepros.v15i1.2293

GEPROS. Gestão da Produção, Operações e Sistemas, v. 15, n 1, p. 92 - 113, 2020. 


\section{INTRODUÇÃO}

As indústrias do setor eletroeletrônico têm como características o alto conhecimento técnico e a mão de obra qualificada, além da necessidade de investimentos em pesquisa e desenvolvimento (P\&D). Segundo Caleiro (2018), os cinco maiores mercados mundiais de eletroeletrônicos em 2017 foram China, Estados Unidos, Índia, Japão e Brasil, nesta ordem. O complexo industrial brasileiro de equipamentos eletroeletrônicos (EEE) é formado por diversos setores industriais que têm em comum a base tecnológica de segmentos de bens de consumo, bens de informática, equipamentos de telecomunicações e componentes eletrônicos (HAUSER et al., 2007).

No Rio Grande do Sul (RS), conforme Bueno (2009), no final do século XIX, as primeiras indústrias de máquinas começaram a surgir, como a Schreiner, de Santa Cruz do Sul que oferecia equipamentos para fábricas de cerâmica. Já em 2011 o setor eletroeletrônico contava com 198 organizações no RS, que geraram um faturamento da ordem de $\mathrm{R} \$ 4,6$ bilhões, o que corresponde a 3,35\% do faturamento nacional do setor (AGDI, 2015). Estas organizações se distribuem em 10 ramos, com destaque para o de Automação Industrial com 83 organizações e que abriga $46 \%$ das organizações brasileiras deste ramo.

Lau et al. (2003) afirmam que a produção e o descarte de equipamentos eletroeletrônicos (EEE) estão afetando o meio ambiente. Assim, as indústrias precisam adotar práticas de gestão socioambiental ao longo de todo seu processo, usando a tecnologia para produzir novos produtos menos agressivos e criando novas maneiras de fazer e distribuir estes produtos (NASCIMENTO; LEMOS; MELLO, 2008).

Cabe ressaltar que há influências na forma que as indústrias de EEE trabalham por parte das exigências legais, como a diretiva WEEE (Waste Electrical and Electronic Equipment) que estabeleceu a responsabilidade dos produtores pelo produto desde a concepção até sua reutilização no processo produtivo ou destinação final (NNOROM; OSIBANJO, 2008; PARLAMENTO EUROPEU, 2015b) e por iniciativas como a Tecnologia da Informação Verde (Green IT) que estuda formas de projetar, fabricar, utilizar e descartar equipamentos de informática e comunicação para que impactem positivamente no meio ambiente (PATÓN-ROMERO et al., 2017). 
Diagnóstico de indústrias de equipamentos eletroeletrônicos do Rio Grande do Sul em relação aos impactos ambientais e sistema de logística reversa

Já o Brasil, em 2010, aprovou a Política Nacional de Resíduos Sólidos (PNRS), que exige que fabricantes, distribuidores e comerciantes estruturem um sistema de logística reversa para produtos eletroeletrônicos (BRASIL, 2010). Entretanto, o acordo setorial, coordenado pelo Ministério do Meio Ambiente, aguarda a realização da consulta pública desde 2014, o que prejudica o atendimento das exigências da PNRS (SINIR, 2018).

Considerando as exigências legais e a crescente preocupação ambiental da sociedade, o problema de pesquisa deste artigo é "como as indústrias de equipamentos eletroeletrônicos do Rio Grande do Sul estão trabalhando para redução do impacto ambiental de sua produção e para atender a legislação ambiental em vigor?”.

Sendo assim, este artigo tem como objetivos avaliar como as indústrias de EEE estão agindo para redução do impacto ambiental de sua produção e também como estão se organizando para atender a legislação ambiental no que se refere aos resíduos destes equipamentos ao final de sua vida útil. Este estudo foi realizado com organizações de equipamentos eletroeletrônicos situadas no estado do Rio Grande do Sul, Brasil.

\section{REFERENCIAL TEÓRICO}

\subsection{A produção e o pós-consumo dos EEE}

Os equipamentos eletroeletrônicos (EEE), segundo Oliveira, Chiesi e Barbieri (2012), possuem substâncias como resina epóxi, fibra de vidro, PCB (Bifenilas policloradas), chumbo, estanho, cobre, silício, berílio, carbono, ferro e alumínio. Lau et al. (2003) afirmam que os EEE podem causar problemas ambientais pelo uso do chumbo e retardantes de chamas, que são uma combinação de Bromo e Antimônio. $O$ chumbo é um metal pesado, bioacumulável e que pode causar enfraquecimento das articulações, aumento de pressão arterial, problemas no sistema digestivo e anemia (TUASAUDE, 2015). Já os retardantes de chamas podem causar câncer e provocar alterações hormonais, afetando o sistema imunológico e reprodutor humano (EPA, 2015).

Sendo assim, foi criada na Europa a diretiva RoHS (Restriction of the Use of certain Hazardous Substances in Electrical and Electronic Equipment) que objetiva eliminar e/ou reduzir substâncias como chumbo, cádmio, mercúrio, cromo e retardantes de chamas nos EEE (PARLAMENTO EUROPEU, 2015a). No Brasil, o Ministério do Meio Ambiente (MMA) adotou medidas para restringir o uso de algumas substâncias, como, por exemplo, estabelecer 
Diagnóstico de indústrias de equipamentos eletroeletrônicos do Rio Grande do Sul em relação aos impactos ambientais e sistema de logística reversa

limites máximos de metais pesados em pilhas e baterias através da Resolução 401 de 04/11/2008 (MMA, 2015a) e criar o projeto BRA/08/G32 para gerir o uso e promover a eliminação progressiva dos PCBs até 2025 (MMA, 2015b). Entretanto, na pesquisa realizada pelo MMA (2018), 12\% das organizações do setor eletroeletrônico participantes disseram não conhecer a Diretiva RoHS europeia e $23 \%$ afirmaram não atender os critérios desta diretiva.

No Brasil, a Política Nacional de Resíduos Sólidos (PNRS) exige implantação da logística reversa para produtos eletroeletrônicos e seus componentes, definindo logística reversa como um sistema que possibilita o retorno de bens ou de seus materiais constituintes ao ciclo produtivo para reaproveitamento ou destinação adequada (BRASIL, 2010). Visando normalizar o uso de substâncias notadamente perigosas em equipamentos eletroeletrônicos (EEE) no Brasil, em 2018 foi criado um Grupo de Trabalho "RoHS Brasileira", coordenado pelo Ministério do Meio Ambiente e contando com participação de várias entidades e órgãos ligados ao setor, como ABINEE (Associação Brasileira da Indústria Elétrica e Eletrônica), ABREE (Associação Brasileira de Reciclagem de Eletroeletrônicos e Eletrodomésticos), ANATEL (Agência Nacional de Telecomunicações), ELETROS (Associação Nacional dos Fabricantes Produtos Eletroeletrônicos) e MCTIC (Ministério da Ciência, Tecnologia, Inovações e Comunicações) (MMA, 2018).

O atendimento da legislação ambiental, conforme Ruiz et al. (2011), traz um aumento no custo de desenvolvimento e produção de EEE, pois demanda novos ensaios, auditorias de qualidade e certificação de fornecedores. Wang e Gupta (2001) afirmam que é possível substituir materiais considerados perigosos na fabricação dos EEE por materiais "verdes", que atendam os requisitos técnicos e sejam recicláveis ou oriundos de fonte renovável.

As soldas com chumbo, por exemplo, largamente utilizadas por terem baixo custo e boas propriedades químicas, físicas e mecânicas, podem ser substituídas por outros tipos de soldas, como o adesivo condutor isotrópico, porém pouco resistentes às fissuras e até 5 vezes mais caros que a de chumbo, afirmam Lau et al. (2003). Já no trabalho realizado por Brescansin et al. (2015), a maior dificuldade apontada pelas organizações participantes para adequação à Diretiva RoHS foi a utilização de solda sem chumbo, por demandar alterações no processo fabril e realização de testes para certificação de componentes.

No trabalho realizado por Ruiz et al. (2011), um dos entrevistados afirma que algumas organizações do setor eletroeletrônico brasileiro adotam matérias primas e procedimentos distintos para atender o mercado europeu e mercado interno. Entretanto, outro entrevistado da GEPROS. Gestão da Produção, Operações e Sistemas, v. 15, nº 1, p. 92 - 113, 2020. 
mesma pesquisa acredita que as organizações que exportam tendem a unificar suas linhas de produção, para minimizar o estoque, e consequentemente o custo, de produtos e componentes.

Braga et al. (2005) defendem que águas de melhor qualidade sejam utilizadas para o abastecimento humano e que as indústrias devem adotar estratégias para reduzir o consumo e utilizar águas de reuso, obtidas após tratamento de seus efluentes ou de outras fontes, como de drenagem agrícola por exemplo. A FIESP (Federação das Indústrias do Estado de São Paulo) elaborou uma cartilha chamada "Gerenciando a escassez de água na indústria" onde propõe que as indústrias avaliem o uso atual da água e elaborem um plano de contingência, visando maior controle da manutenção de equipamentos de distribuição de água na empresa e avaliando a possibilidade de realizar tratamento de suas águas residuais para reuso em algum processo (ELETROS, 2015; FIESP, 2015).

Outro fator importante para reduzir o impacto ambiental da produção de EEE é utilizar métodos que consumam menos energia elétrica, além de utilizar fontes de energia renováveis como a solar e a eólica (GREENPEACE, 2015). Kobal et al. (2014) apresenta um estudo sobre o uso da água e da energia, dentre outros fatores pesquisados, que foi realizado com 60 organizações do setor eletroeletrônico do Brasil distribuídas em 8 estados brasileiros e os resultados apresentados não evidenciam ações de reaproveitamento de água em praticamente metade das organizações pesquisadas, bem como 65\% destas organizações não utilizam nenhuma fonte de energia alternativa.

Em maior ou menor escala, todo produto afeta o ambiente e produz algum tipo de poluição, afirmam Nascimento, Lemos e Mello (2008). A concepção de um novo produto é uma fase importante, pois define as características, os materiais e o design deste produto. Os autores apresentam o conceito de ecodesign como sendo integrador das questões ambientais e industriais, que busca alternativas para otimizar o uso de recursos naturais, minimizar o uso de energia e permitir a reciclagem após a vida útil. Reciclabilidade, segundo Leite (2009), trata da adequação técnica nas diversas fases do produto, considerando fatores como facilidade de desmontagem, de separação das peças e de extração de materiais.

A pesquisa de Kobal et al. (2014) mostra a preocupação das organizações com a durabilidade e possibilidade de reparação dos equipamentos e com a otimização do tipo e quantidade de materiais utilizados nos produtos. Entretanto, não foi evidenciada entre as organizações pesquisadas pelos autores a realização de projetos que visem a reciclabilidade 
do produto. Em relação às embalagens, $67 \%$ das organizações pesquisadas utilizam embalagens recicláveis na maioria de seus produtos.

Os resíduos dos equipamentos eletroeletrônicos (REEE) podem retornar ao processo produtivo após a reciclagem ou serem reutilizados em aplicações diversas. A responsabilidade pela gestão dos REEE é dos fabricantes, distribuidores, importadores e comerciantes, segundo a PNRS, que precisam estruturar um sistema de logística reversa (BRASIL, 2010). Leite (2009) enfatiza que as organizações implantam sistemas de logística reversa motivadas por exigências legais, mudança de comportamento da sociedade exigindo a responsabilidade ambiental das organizações e preocupação com a imagem corporativa.

O Greenpeace, desde 2006, desafia as principais organizações mundiais do setor eletroeletrônico a reduzir seus impactos ambientais, eliminando o uso de substâncias perigosas e promovendo a reciclagem dos produtos. Um dos resultados apresentados mostra que em 2006 todos os aparelhos celulares pesquisados continham substâncias perigosas e que em 2014 este número foi reduzido à metade (GREENPEACE, 2015).

Além disso, o Greenpeace elabora o Guide to Greener Electronics (Guia dos eletrônicos verdes). Este guia classifica os grandes fabricantes considerando três fatores: energia, produtos e operações (GREENPEACE, 2012). Em relação à energia, as organizações devem apresentar ações para redução de gases de efeito estufa e utilização de energia limpa. Os produtos precisam reduzir consumo de recursos, possuir design sustentável e reciclabilidade. Já em relação às operações, as organizações devem buscar a eliminação de substâncias tóxicas dos produtos e na manufatura (GREENPEACE, 2012; GREENPEACE, 2017). A Figura 1 apresenta o ranking do Greepeace em 2017. Percebe-se que a Fairphone apresentou desempenho levemente superior às demais neste ranking, seguida por Apple, HP, Dell, Lenovo e Microsoft, posicionadas em área intermediária da Figura. As demais organizações tiveram desempenho inferior, o que mostra que as organizações ainda precisam melhorar seus produtos e processos em relação ao uso sustentável do meio ambiente. 
Figura 1 - Guide to Greener Electronics - 2017

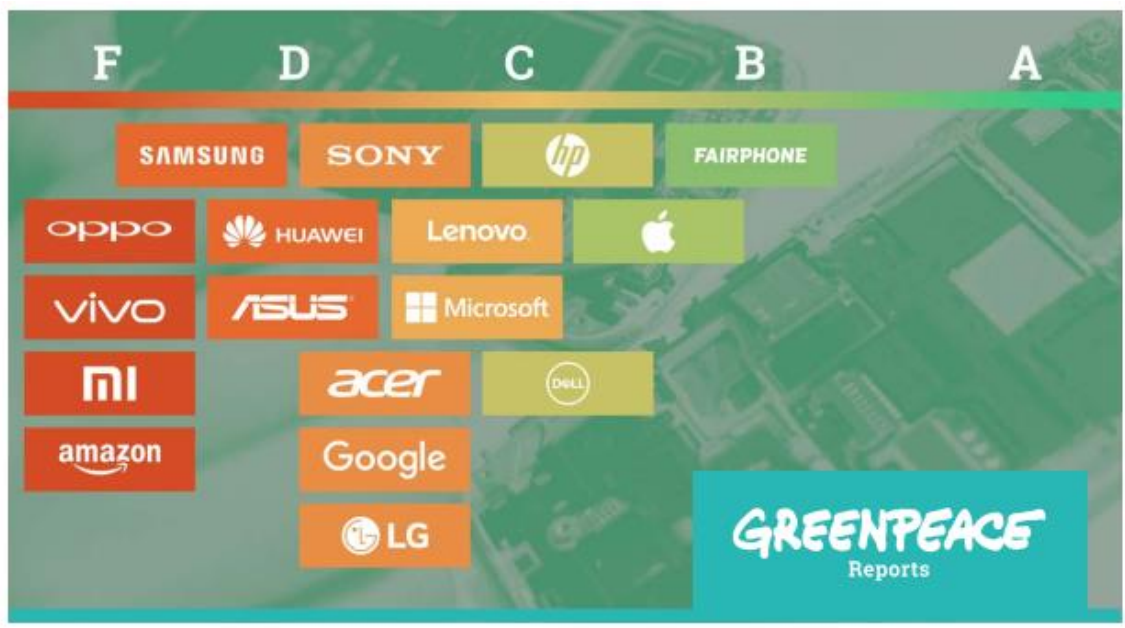

Fonte: Greenpeace (2017).

\section{PROCEDIMENTOS METODOLÓGICOS}

A pesquisa realizada é de natureza aplicada, uma vez que desenvolve conhecimentos com aplicações práticas, segundo Kauark, Manhães e Medeiros (2010). Também pode ser definida como descritiva, pois detalha características ou funções de um determinado setor. Do ponto de vista da abordagem, é uma pesquisa quantitativa, já que utiliza uma coleta de dados estruturada e analisa os dados de forma estatística. O levantamento de campo foi o método aplicado para coleta de dos junto aos entrevistados (MALHOTRA, 2011).

$\mathrm{Na}$ etapa de planejamento da pesquisa foram definidos os objetivos, a população objeto da pesquisa, o instrumento de coleta de dados e as ferramentas para análise de dados. A amostragem utilizada foi não probabilística intencional (KAUARK; MANHÃES; MEDEIROS, 2010). Foram determinados critérios de seleção das organizações a serem contatadas: deveria estar localizada no Rio Grande do Sul e ser fabricante de equipamentos eletroeletrônicos.

A lista inicial das organizações a serem contatadas foi obtida no documento Pesquisa de Desempenho Setorial, da ABINEE, e contava com 198 organizações (ABINEE, 2011). Esta listagem foi escolhida em função da entidade ser representante das indústrias do setor e por disponibilizar na internet a listagem das organizações associadas no estado. Após análise percebeu-se que algumas eram prestadoras de serviço, principalmente na área de informática, e estas foram excluídas da pesquisa por não se enquadrarem nos critérios estabelecidos. A lista que foi utilizada contava com 119 organizações. Todas as 119 organizações foram GEPROS. Gestão da Produção, Operações e Sistemas, v. 15, nº 1, p. 92 - 113, 2020. 
Diagnóstico de indústrias de equipamentos eletroeletrônicos do Rio Grande do Sul em relação aos impactos ambientais e sistema de logística reversa

contatadas via e-mail, facilitador ou telefone para informar os objetivos da pesquisa, sendo que 19 aceitaram participar da pesquisa.

O instrumento de coleta de dados escolhido foi o questionário estruturado. Para elaboração do instrumento foram consideradas principalmente as exigências da Política Nacional de Resíduos Sólidos para equipamentos eletroeletrônicos (BRASIL, 2010) e informações obtidas no referencial teórico deste trabalho. O questionário, após realização do pré-teste, foi enviado por e-mail para as organizações selecionadas, sendo devolvido com respostas da mesma forma. A coleta de dados foi realizada entre março e julho de 2015.

A parte principal do questionário está dividida em quatro blocos com questões fechadas, onde os representantes da empresa informavam a concordância ou não com a afirmação, numa escala Likert de 5 pontos, sendo que o 1 representa o "discorda totalmente". No bloco 1 constam afirmativas sobre o processo produtivo, do uso da água e da energia e da destinação dos resíduos de produção. Já o bloco 2 trata dos produtos da empresa, da composição destes produtos, dos fornecedores de matérias primas e da possiblidade de desmanche destes produtos ao fim da vida útil. O terceiro bloco trata do relacionamento da empresa com consumidores, de como são disponibilizadas as informações sobre o transporte, uso e descarte dos equipamentos e embalagens. O último bloco trata da implantação da Política Nacional dos Resíduos Sólidos. Para que não houvesse tendência do respondente em concordar com todas as afirmações foi tomado o cuidado de inverter o sentido de algumas afirmações, para que a resposta esperada pelos pesquisadores fosse a discordância.

Após foi realizada a avaliação da consistência interna dos dados obtidos pela aplicação do questionário, por meio do cálculo do Alfa de Cronbach (FIPECAFI, 2007). Para atender a premissa deste modelo de análise de confiabilidade, foram calculadas as correlações entre as questões, garantindo que estas correlações fossem positivas, invertendo o sentido de direção sempre que a resposta esperada fosse a discordância da afirmação. O Alfa de Cronbach obtido, utilizando o software SPSS, foi de 0,797 , valor que mostra que o questionário foi compreendido pelos respondentes, uma vez que o valor é superior a 0,7 , limiar de aceitação segundo Hair et al. (2005).

Para medir a associação entre duas variáveis ordinais, como neste estudo empregou-se a escala Likert de 5 pontos, foi utilizado o coeficiente de correlação posto-ordem $r_{s}$ de Spearman para verificar o grau desta associação, com determinado nível de significância $\alpha$. Esta medida de associação foi escolhida devido ao fato que ela expressa o nível de GEPROS. Gestão da Produção, Operações e Sistemas, v. 15, nº 1, p. 92 - 113, 2020. 
Diagnóstico de indústrias de equipamentos eletroeletrônicos do Rio Grande do Sul em relação aos impactos ambientais e sistema de logística reversa

concordância das afirmações. Segundo Siegel (2006), para pequenas amostras, é possível verificar se duas variáveis estão associadas comparando o valor obtido para $r_{\mathrm{s}} \mathrm{e}$ um valor crítico determinado pelo tamanho da amostra e nível de significância desejado. Mesmo a amostra deste estudo não sendo aleatória, procedeu-se a verificação da significância para todas as variáveis, visando o atendimento dos critérios técnicos do teste. No caso deste trabalho, o tamanho da amostra é $n=19$ e o nível de significância desejado é $\alpha=0,05$, resultando em um valor crítico de 0,584 .

Além da averiguação das associações, foi criado um índice com o objetivo de classificar as organizações participantes da pesquisa. Este índice geral $\left(\mathrm{IG}_{\mathrm{k}}\right)$ é calculado através do somatório das respostas obtidas no questionário, para cada empresa, considerando a resposta esperada ou mais adequada por atender requisitos ambientais e legais de cada questão. Por exemplo, na questão 1 do bloco 1, a resposta mais adequada é a concordância total (5) com a afirmação, pois espera-se que as organizações já tenham tomado medidas para reduzir os resíduos gerados durante a produção. Entretanto, na questão 4 do mesmo bloco, espera-se que as organizações acompanhem de alguma forma o processo de reciclagem e destinação final de seus resíduos produtivos e a melhor resposta para a afirmação da questão seria a discordância total (1). O índice $\mathrm{IG}_{\mathrm{k}}$ é obtido através da equação 1 , onde $k$ representa cada empresa.

$$
I G_{k}=\sum_{i=1}^{i=b} I_{i}
$$

Os subíndices $I_{i}$ são calculados dentro de cada bloco do questionário, segundo a equação 2 , sendo $b$ o número de blocos do questionário, $R_{j}$ a as respostas dada para cada questão e $m$ o número de questões de cada bloco.

$$
I_{i}=\sum_{j=1}^{j=m} R_{j}
$$

Entretanto, como algumas questões em cada bloco tem como resposta mais adequada o valor mais baixo e não o mais alto da escala é preciso realizar uma operação de inversão do sentido destas respostas, para que o peso de todas as questões seja semelhante. No caso do questionário utilizado nesta pesquisa, no bloco 1 é preciso realizar a operação nas questões 3 e 4 , no bloco 2 e 3 é preciso inverter as questões 2 e 3 e no último bloco é preciso alterar as questões 2, 3 e 6 . A operação de inversão do sentido é apresentada na equação 3. Note-se que uma discordância total $\left(\mathrm{R}_{\mathrm{j}}=1\right)$ entrará na contabilidade do $\mathrm{IG}_{\mathrm{k}}$ como $\mathrm{R}_{\mathrm{j} *=5} \mathrm{e}$, portanto, terá o GEPROS. Gestão da Produção, Operações e Sistemas, v. 15, nº 1, p. 92 - 113, 2020. 
mesmo peso no cálculo do indicie geral que uma concordância total nas questões com respostas diretas.

$$
R_{j *}=\left(5-R_{j}\right)+1
$$

\section{RESULTADOS E DISCUSSÕES}

A pesquisa realizada pela setorial gaúcha da ABINEE (2011) mostrou que $67 \%$ das organizações do setor eletroeletrônico do RS estavam localizadas na região metropolitana de Porto Alegre, mais precisamente entre a capital e a cidade de Novo Hamburgo, $16 \%$ ficavam na cidade de Caxias do Sul e as $17 \%$ restantes estavam distribuídas em outras cidades. Neste trabalho a distribuição geográfica das organizações que participaram do estudo foi de $74 \%$ das organizações localizadas na região metropolitana de Porto Alegre, 16\% na região Nordeste (Caxias do Sul e Guaporé) e $10 \%$ na região Central do RS. Nota-se que a proporção das organizações participantes assemelha-se ao apresentado pela ABINEE.

Em relação ao porte das organizações, foi utilizado o critério do número de funcionários para fazer a classificação por considerar que este dado seria facilmente fornecido pelas organizações. As indústrias foram classificadas em: (i) Microempresa: até 19 funcionários; (ii) Pequena empresa: de 20 a 99 funcionários; (iii): Média empresa: de 100 a 499 funcionários e; (iv) Grande empresa: mais de 500 funcionários (SEBRAE, 2014). Neste trabalho, a classificação das 19 organizações participantes foi: 3 são micro organizações, 6 são pequenas organizações, 8 são médias organizações e 2 são grandes organizações.

A maioria dos questionários foi respondida por pessoa da área da Qualidade (32\%) ou Diretoria (26\%). Em relação ao comércio exterior, oito organizações (42\%) afirmaram ser exportadoras de seus produtos e 11 se dedicam apenas ao mercado interno. Em relação aos destinos das exportações, pode-se afirmar que todas as organizações exportadoras enviam seus produtos para países da América do Sul, duas organizações exportam também para a América Latina e quatro exportam para a Europa e outros continentes.

\subsection{Análise por blocos do questionário}

O Bloco 1 do questionário traz afirmações relativas ao processo produtivo da empresa, visando conhecer se há preocupação em reduzir resíduos gerados durante a produção e sua GEPROS. Gestão da Produção, Operações e Sistemas, v. 15, nº 1, p. 92 - 113, 2020. 
Diagnóstico de indústrias de equipamentos eletroeletrônicos do Rio Grande do Sul em relação aos impactos ambientais e sistema de logística reversa

destinação, bem como reduzir o consumo de energia e água, corroborando com Braga et al. (2005) que defendem que as organizações devem evitar a geração da poluição e conservar recursos e energia. A distribuição das respostas, quantidade de respostas para cada opção e percentual em relação ao total de organizações, é mostrada na Tabela 1.

Tabela 1 - Distribuição das respostas do Bloco 1

\begin{tabular}{|c|c|c|c|c|c|c|}
\hline Bloco 1 - Processo produtivo & Respostas & 1 & 2 & 3 & 4 & 5 \\
\hline \multirow{2}{*}{$\begin{array}{l}\text { 1. A empresa já alterou processos produtivos para reduzir a } \\
\text { geração de resíduos de produção. }\end{array}$} & Quant & 0 & 1 & 0 & 7 & 11 \\
\hline & $\%$ & $0 \%$ & $5 \%$ & $0 \%$ & $37 \%$ & $58 \%$ \\
\hline \multirow{2}{*}{$\begin{array}{l}\text { 2. Os resíduos gerados na produção são encaminhados para } \\
\text { gerenciadoras ou cooperativas específicas para cada tipo de } \\
\text { resíduos. }\end{array}$} & Quant & 0 & 1 & 1 & 2 & 15 \\
\hline & $\%$ & $0 \%$ & $5 \%$ & $5 \%$ & $11 \%$ & $79 \%$ \\
\hline \multirow{2}{*}{$\begin{array}{l}\text { 3. Os resíduos da produção são encaminhados para a coleta } \\
\text { pública. }\end{array}$} & Quant & 13 & 2 & 0 & 4 & 0 \\
\hline & $\%$ & $68 \%$ & $11 \%$ & $0 \%$ & $21 \%$ & $0 \%$ \\
\hline \multirow{2}{*}{$\begin{array}{l}\text { 4. O processo de reciclagem e destinação final de seus } \\
\text { resíduos produtivos são realizados sem acompanhamento da } \\
\text { empresa. }\end{array}$} & Quant & 7 & 2 & 4 & 2 & 4 \\
\hline & $\%$ & $37 \%$ & $11 \%$ & $21 \%$ & $11 \%$ & $21 \%$ \\
\hline \multirow{2}{*}{$\begin{array}{l}\text { 5. A empresa já alterou seus processos produtivos visando } \\
\text { reduzir o consumo de energia e água durante a fabricação de } \\
\text { seus produtos. }\end{array}$} & Quant & 1 & 0 & 2 & 6 & 10 \\
\hline & $\%$ & $5 \%$ & $0 \%$ & $11 \%$ & $32 \%$ & $53 \%$ \\
\hline
\end{tabular}

Fonte: Autores

As respostas das organizações para a primeira questão deste bloco mostram que praticamente todas já alteraram seus processos de produção para reduzir resíduos gerados durante a fabricação de seus produtos. Também se pode perceber nas questões 2 e 3 que a maioria das organizações pesquisadas (79\%) encaminham estes resíduos para organizações especializadas na gestão de resíduos e não para a coleta pública. Já a questão 4 mostra que não é procedimento de algumas organizações acompanhar a destinação dos seus resíduos. Em relação ao consumo de água e energia, 16 organizações afirmaram ter alterado o processo produtivo para reduzir estes consumos.

O Bloco 2 apresenta questões relativas aos produtos das organizações e a distribuição de frequências é mostrado na Tabela 2. Para as quatro organizações que exportam para a Europa, esperava-se que a Diretiva RoHS (PARLAMENTO EUROPEU, 2015a) estivesse sendo atendida e que seus produtos estivessem isentos de substâncias proibidas pela diretiva. Entretanto, ao analisar as questões 1 e 2 deste bloco, verifica-se que duas das organizações que exportam para a Europa atendem tal diretiva e apenas uma afirmou que todos seus produtos não contêm chumbo, cromo, mercúrio, cádmio e retardantes de chamas. Isso reforça GEPROS. Gestão da Produção, Operações e Sistemas, v. 15, nº 1, p. 92 - 113, 2020. 
Diagnóstico de indústrias de equipamentos eletroeletrônicos do Rio Grande do Sul em relação aos impactos ambientais e sistema de logística reversa

a afirmação apresentada no trabalho de Ruiz et al. (2011) de que algumas organizações mantêm linhas de produtos distintas para exportação e atendimento do mercado interno. Outro ponto preocupante é que a presença destas substâncias é admitida por quase metade das organizações. Positivamente, salienta-se que três organizações que não exportam seus produtos afirmaram atender a Diretiva RoHS.

Tabela 2 - Distribuição das respostas do Bloco 2

\begin{tabular}{|c|c|c|c|c|c|c|}
\hline Bloco 2 - Produtos & Respostas & 1 & 2 & 3 & 4 & 5 \\
\hline \multirow{2}{*}{$\begin{array}{l}\text { 1. A empresa atende as exigências da Diretiva ROHS na } \\
\text { fabricação dos produtos destinados à Comunidade Europeia } \\
\text { ou países com as restrições semelhantes. }\end{array}$} & Quant & 6 & 3 & 2 & 2 & 6 \\
\hline & $\%$ & $32 \%$ & $16 \%$ & $11 \%$ & $11 \%$ & $32 \%$ \\
\hline \multirow{2}{*}{$\begin{array}{l}\text { 2. Os produtos da empresa possuem substâncias como } \\
\text { chumbo, cromo, mercúrio, cádmio e retardantes de chamas. }\end{array}$} & Quant & 6 & 1 & 2 & 5 & 5 \\
\hline & $\%$ & $32 \%$ & $5 \%$ & $11 \%$ & $26 \%$ & $26 \%$ \\
\hline \multirow{2}{*}{$\begin{array}{l}\text { 3. A empresa desonera seus fornecedores do atendimento às } \\
\text { exigências da Diretiva ROHS. }\end{array}$} & Quant & 6 & 1 & 6 & 5 & 1 \\
\hline & $\%$ & $32 \%$ & $5 \%$ & $32 \%$ & $26 \%$ & $5 \%$ \\
\hline \multirow{2}{*}{$\begin{array}{l}\text { 4. A empresa busca designs que facilitem a desmontagem, o } \\
\text { reaproveitamento e a reciclagem dos equipamentos. }\end{array}$} & Quant & 2 & 3 & 4 & 5 & 5 \\
\hline & $\%$ & $11 \%$ & $16 \%$ & $21 \%$ & $26 \%$ & $26 \%$ \\
\hline
\end{tabular}

Fonte: Autores

Observando as respostas da questão 3, percebe-se que seis organizações (32\%) exigem que seus fornecedores atendam as exigências da Diretiva RoHS. Já ao analisar a questão 4 deste bloco, nota-se que 52\% das organizações afirmam ter alguma preocupação com o design dos produtos, com a sua reciclabilidade.

O bloco 3 do questionário trata de questões sobre as informações que a empresa passa para seus consumidores sobre os produtos e suas embalagens. O primeiro questionamento era sobre informações sobre destinação correta do produto após sua vida útil, sendo que somente quatro respondentes (21\%) disseram fornecer algum tipo de informação. Pode-se perceber nos gráficos de distribuição de frequência da Tabela 3 que a maioria das organizações não fornece estas informações, pois discordaram totalmente da afirmação. 
Diagnóstico de indústrias de equipamentos eletroeletrônicos do Rio Grande do Sul em relação aos impactos ambientais e sistema de logística reversa

Tabela 3 - Distribuição das respostas do Bloco 3

\begin{tabular}{llccccc}
\hline Bloco 3 - Informações aos cons umidores & Respostas & $\mathbf{1}$ & $\mathbf{2}$ & $\mathbf{3}$ & $\mathbf{4}$ & $\mathbf{5}$ \\
\hline $\begin{array}{l}\text { 1. As embalagens dos produtos da empresa oferecem } \\
\text { informações sobre a destinação correta do produto após sua }\end{array}$ & Quant & 11 & 2 & 2 & 1 & 3 \\
vida útil. & $\%$ & $58 \%$ & $11 \%$ & $11 \%$ & $5 \%$ & $16 \%$ \\
$\begin{array}{l}\text { 2. As informações sobre descarte, transporte, manuseio e } \\
\text { armazenagem do produto são de exclusividade da empresa. }\end{array}$ & Quant & 5 & 0 & 4 & 5 & 5 \\
3. Não são fornecidas informações sobre a destinação das & Quant & $26 \%$ & $0 \%$ & $21 \%$ & $26 \%$ & $26 \%$ \\
embalagens dos produtos da empresa. & $\%$ & $21 \%$ & $16 \%$ & 6 & 1 & 5 \\
$\begin{array}{l}\text { 4. A empresa disponibiliza informações sobre os pontos de } \\
\text { coleta dos seus equipamentos após sua vida útil. }\end{array}$ & Quant & 9 & 0 & 5 & 1 & $26 \%$ \\
\hline
\end{tabular}

Fonte: Autores.

Nas questões 2 e 3 do Bloco 3 não houve predominância de respostas, o que mostra que a maioria das organizações não costuma disponibilizar informações sobre transporte, manuseio, armazenagem e destinação correta dos produtos e das embalagens. A última questão deste bloco versa sobre os pontos de coleta para os equipamentos após vida útil e novamente percebe-se que esta informação não é disponibilizada para os consumidores, exceção para cinco (26\%) das dezenove organizações pesquisadas.

O último bloco de questões trata da Política Nacional dos Resíduos Sólidos (PNRS) e a distribuição de frequências é apresentada na Tabela 4. As duas primeiras questões deste bloco tratam do Plano de Gerenciamento de Resíduos Sólidos, um instrumento da PNRS que é obrigatório para indústrias (BRASIL, 2010). Nota-se que doze organizações estão como este plano concluído (63\%) e oito (42\%) já implantaram as ações previstas no plano. 
Diagnóstico de indústrias de equipamentos eletroeletrônicos do Rio Grande do Sul em relação aos impactos ambientais e sistema de

Tabela 4 - Distribuição das respostas do Bloco 4

\begin{tabular}{|c|c|c|c|c|c|c|}
\hline Bloco 4 - Política Nacional de Resíduos Sólidos & Respostas & 1 & 2 & 3 & 4 & 5 \\
\hline \multirow{2}{*}{$\begin{array}{l}\text { 1. A empresa elaborou seu plano de gerenciamento de } \\
\text { resíduos sólidos conforme legislação vigente. }\end{array}$} & Quant & 1 & 1 & 3 & 2 & 12 \\
\hline & $\%$ & $5 \%$ & $5 \%$ & $16 \%$ & $11 \%$ & $63 \%$ \\
\hline \multirow{2}{*}{$\begin{array}{l}\text { 2. As ações propostas no plano de gerenciamento de } \\
\text { resíduos sólidos ainda não foram implantadas. }\end{array}$} & Quant & 8 & 1 & 2 & 6 & 2 \\
\hline & $\%$ & $42 \%$ & $5 \%$ & $11 \%$ & $32 \%$ & $11 \%$ \\
\hline \multirow{2}{*}{$\begin{array}{l}\text { 3. A empresa está alheia à discussão a respeito da } \\
\text { implantação da logística reversa para equipamentos } \\
\text { eletroeletrônicos, diretamente ou através de sua entidade } \\
\text { representativa. }\end{array}$} & Quant & 7 & 3 & 5 & 0 & 4 \\
\hline & $\%$ & $37 \%$ & $16 \%$ & $26 \%$ & $0 \%$ & $21 \%$ \\
\hline \multirow{2}{*}{$\begin{array}{l}\text { 4. A empresa disponibiliza pontos de coleta, próprios ou } \\
\text { terceirizados, para descarte de seus produtos. }\end{array}$} & Quant & 8 & 0 & 5 & 0 & 6 \\
\hline & $\%$ & $42 \%$ & $0 \%$ & $26 \%$ & $0 \%$ & $32 \%$ \\
\hline $\begin{array}{l}\text { 5. A destinação e tratamento correto dos resíduos } \\
\text { eletroeletrônicos da empresa são realizados por empresa }\end{array}$ & Quant & 2 & 0 & 1 & 2 & 14 \\
\hline Gerenciadora de Resíduos. & $\%$ & $11 \%$ & $0 \%$ & $5 \%$ & $11 \%$ & $74 \%$ \\
\hline \multirow{2}{*}{$\begin{array}{l}\text { 6. Nem todos os produtos da empresa são contemplados com } \\
\text { o processo de logística reversa. }\end{array}$} & Quant & 5 & 1 & 3 & 1 & 9 \\
\hline & $\%$ & $26 \%$ & $5 \%$ & $16 \%$ & $5 \%$ & $47 \%$ \\
\hline
\end{tabular}

Fonte: Autores

A terceira questão do Bloco 4 visava avaliar a participação das organizações na discussão sobre a PNRS e a obrigatoriedade da implantação da logística reversa para os equipamentos eletroeletrônicos (EEE). As indústrias tem papel fundamental na elaboração do acordo setorial que está sendo elaborado juntamente com o Ministério do Meio Ambiente, pois serão responsáveis pelo sistema de logística reversa, juntamente com comerciantes, importadores e distribuidores de EEE (SINIR, 2018). Dez respondentes (53\%) afirmaram acompanhar este processo, diretamente ou através de sua entidade representativa.

A disponibilização de pontos de coleta para descarte dos EEE é o assunto da quarta questão do Bloco 4. Seis organizações (32\%) disponibilizam estes pontos de coleta, oito organizações (42\%) não disponibilizam e cinco organizações (26\%) não se posicionaram em relação aos pontos de coleta. Em relação ao tratamento dos resíduos dos equipamentos eletroeletrônicos (REEE), esta tarefa é realizada por organizações especializadas em gestão de resíduos para quatorze organizações $(74 \%)$. A última questão indagava sobre a realização da logística reversa para os produtos da empresa, sendo que somente cinco organizações $(26 \%)$ contemplam todos os produtos da empresa com a logística reversa. 


\subsection{Análise da associação entre questões}

Foi a verificação da associação entre as questões pesquisadas utilizando o coeficiente de correlação posto-ordem de Spearman $\left(\mathrm{r}_{\mathrm{s}}\right)$, sendo que este foi obtido utilizando-se o software SPSS (versão 18). Conforme recomendado por Siegel (2006), as associações com significância ao nível de 5\% $(\alpha=0,05)$, neste caso, ocorre para valor quando $\mathrm{r}_{\mathrm{s}} \geq 0,584$. $\mathrm{O}$ sinal negativo indica que uma das questões tinha sentido inverso e a discordância seria a resposta esperada. Da análise dos valores obtidos, destacam-se duas associações que apresentaram os maiores valores para o coeficiente, em módulo.

A associação que apresentou coeficiente de Spermann mais elevado $(-0,691)$ foi entre a questão 3 do Bloco 1 (encaminhamento dos resíduos de produção para a coleta pública) e a questão 1 do Bloco 4 (elaboração do plano de gerenciamento de resíduos sólidos), mostrando que as organizações que elaboraram o plano de gerenciamento não encaminham resíduos produtivos para a coleta pública. A PNRS exige que os planos de gerenciamento de resíduos sólidos contemplem, ao menos, um diagnóstico dos resíduos gerados e a definição de responsáveis e procedimentos do gerenciamento de resíduos (BRASIL, 2010).

O segundo maior coeficiente de Spearmann $(-0,689)$ foi o da associação entre a questão 4 do Bloco 3, que indaga sobre o design dos produtos, e a 6 do Bloco 4, que questiona se a empresa contempla todos os seus produtos com o sistema de logística reversa. Este resultado mostra que organizações que implantaram sistemas de logística reversa para todos os produtos apresentam preocupação com o design de seus produtos para facilitar a posterior reciclagem.

\subsection{Classificação das organizações}

Com o objetivo de classificar as organizações, foram calculados os índices gerais $\left(\mathrm{IG}_{\mathrm{k}}\right)$ e índices de cada bloco do questionário $\left(\mathrm{I}_{1}, \mathrm{I}_{2}, \mathrm{I}_{3}\right.$ e $\left.\mathrm{I}_{4}\right)$ para cada empresa $(\mathrm{k})$. Os limites dos eixos horizontais foram definidos com base nos valores máximos e mínimos que poderiam ser encontrados para o índice, depois de aplicada a operação de inversão da equação 3, quando necessário. Por exemplo, o $\mathrm{I}_{1}$ é composto por 5 questões que podem ter como resposta de $1 \mathrm{a}$ 5 , logo o mínimo que a empresa pode obter é 5 ( 5 x 1) e o máximo é 25 (5 x 5). As cores dos gráficos foram definidas dividindo o intervalo entre os valores mínimos e máximos em quatro partes iguais $(25 \%)$ e cada parte foi identificada com uma cor, sendo a primeira vermelha e a 
Diagnóstico de indústrias de equipamentos eletroeletrônicos do Rio Grande do Sul em relação aos impactos ambientais e sistema de logística reversa

última verde. Os números que identificam os pontos dos gráficos representam as organizações que participaram da pesquisa e variam de 1 a 19.

O Gráfico resultante para o índice $\mathrm{I}_{1}$ é mostrado na Figura 2a. Nota-se que a maioria das organizações encontra-se na área verde do gráfico, o que evidencia que estão buscando melhorias em seus processos produtivos, através da redução do consumo de água e energia, bem como demonstrando preocupação com a destinação dos resíduos da produção.

Figura 2 - Gráficos para índices de cada bloco de questões

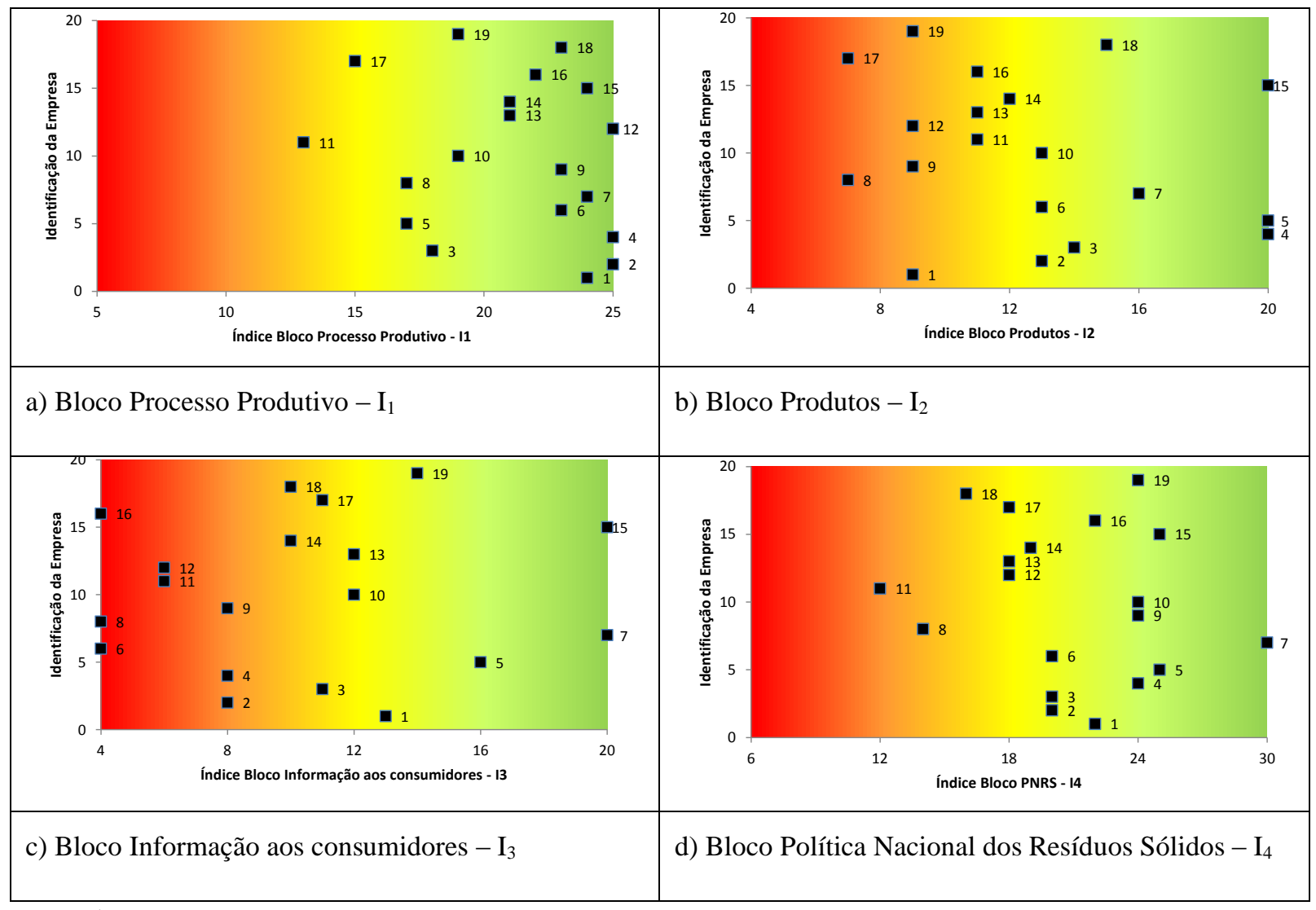

Fonte: Autores.

A Figura $2 \mathrm{~b}$ apresenta o gráfico resultante para o índice $\mathrm{I}_{2}$, que mostra que a maioria das organizações encontra-se na esquerda do gráfico, evidenciando que ainda não alteraram os produtos para substituir substâncias consideradas nocivas para o ser humano e meio ambiente, independente de ser ou não exigência legal. Além disso, há pouca preocupação com a reciclabilidade dos produtos em grande parte das organizações pesquisadas, mas cabe destacar que 3 organizações obtiveram o valor máximo para este índice.

$\mathrm{O}$ índice do Bloco Informações aos consumidores $\left(\mathrm{I}_{3}\right)$ está representado na Figura 2c.

O valor máximo para este índice foi obtido por duas organizações. A maioria das GEPROS. Gestão da Produção, Operações e Sistemas, v. 15, nº 1, p. 92 - 113, 2020. 
organizações ficou na parte inferior do gráfico, o que demonstra que as informações sobre o manuseio do produto durante a vida útil e sobre a destinação do produto após o uso não são disponibilizadas para os consumidores, ou são insuficientes.

A Figura 2d traz o gráfico para o índice $\mathrm{I}_{4}$, referente ao Bloco da PNRS. Percebe-se um agrupamento no lado direito do gráfico, evidenciando que a maioria das organizações caminha para o atendimento de pontos importantes da PNRS, como a elaboração de planos de gerenciamento de resíduos e participação na discussão da implantação da logística reversa para os resíduos eletroeletrônicos. Ressalta-se que apenas uma empresa alcançou o valor máximo para este índice.

$\mathrm{O}$ índice que aglutina as informações dos quatro blocos é o $\mathrm{IG}_{\mathrm{k}}$ mostrado na Figura 3. Duas organizações (7 e 15) apresentaram desempenho superior às demais e seus índices gerais próximos ao limite máximo. Estas duas organizações localizam-se na região metropolitana de Porto Alegre e são classificadas como sendo de grande porte. Outras duas organizações (4 e 5) também encontram-se nos últimos $25 \%$ da escala. Pode-se considerar que estas quatro organizações apresentam maior preocupação com o impacto de sua produção e resíduos de seus produtos e que estão mais organizadas para o atendimento de requisitos ambientais e legais.

Observa-se também na Figura 3 que a maioria das organizações encontra-se na área intermediária do gráfico e que duas organizações (8 e 11) obtiveram índices bem abaixo das demais. Estas organizações com menores índices localizam-se em Porto Alegre e são classificadas como micro ou pequena empresa. Este resultado mostra que é preciso investimentos e incentivos nas organizações de menor porte para melhorar os processos produtivos e a composição dos produtos para possibilitar a implantação da logística reversa exigida na PNRS. 
Figura 3 - Índice geral

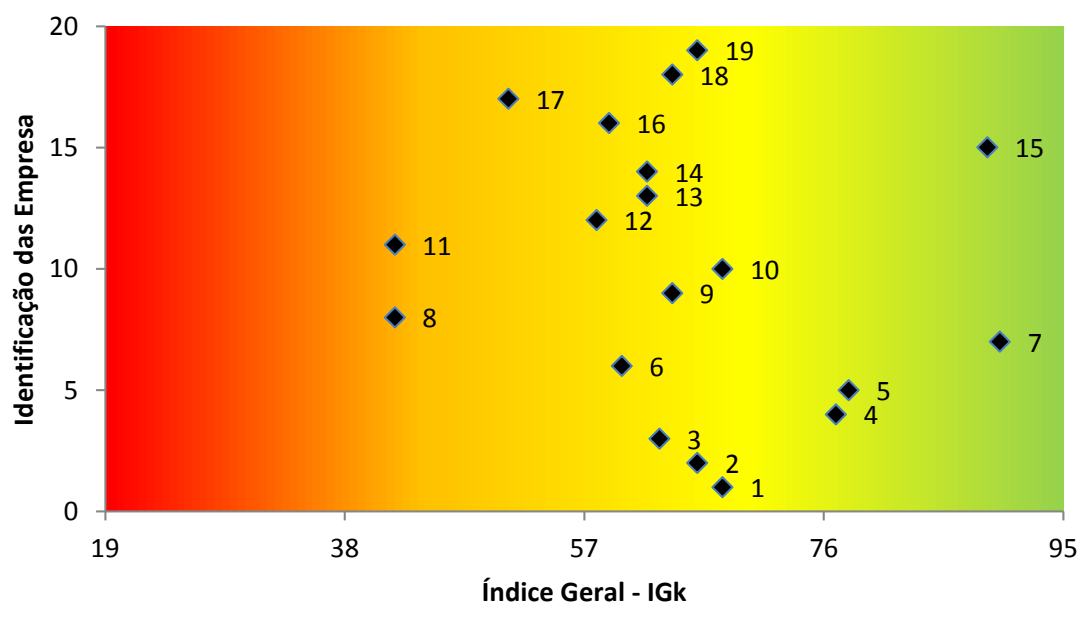

Fonte: Autores.

\section{CONCLUSÕES}

Avaliando os resultados apresentados na pesquisa, percebe-se que as organizações participantes têm trabalhado para melhoria de seus processos produtivos, reduzindo a geração de resíduos e dando a eles a destinação correta, bem como reduzindo o consumo de água e energia. Sendo assim, a maioria das organizações demonstra preocupação em minimizar impactos ambientais gerados durante o processo de produção dos seus equipamentos.

Entretanto, em relação aos produtos e sua composição, nota-se que muitas organizações ainda não alteraram seus projetos para que utilizem matérias primas menos agressivas ou para modificar o design para facilitar a desmontagem e posterior reaproveitamento ou reciclagem destes produtos. Em relação às matérias primas, há necessidade de restringir o uso de determinadas substâncias para que os produtos nacionais possam competir no mercado europeu, mas também é importante restringir o uso de metais pesados para produtos consumidos no mercado interno, reduzindo o impacto ambiental no país e na população local.

Observando os resultados sobre as informações que são disponibilizadas aos consumidores se constata que as organizações não costumam fornecer informações sobre descarte (formas e locais), cuidados no armazenamento e transporte dos produtos. Estas informações precisam ser claras e facilmente localizadas pelos consumidores, nas 
embalagens, manuais ou internet, pois estes são os responsáveis por descartar corretamente os produtos e dar início ao processo de logística reversa.

No bloco sobre a Política Nacional dos Resíduos Sólidos (PNRS) percebe-se que as organizações que elaboraram e implantaram seus planos de gerenciamento de resíduos sólidos começam a apresentar como resultados uma gestão responsável de seus resíduos. A questão dos resíduos eletroeletrônicos e o sistema de logística reversa exigido pela PNRS ainda não é realidade na maioria das organizações pesquisadas, uma vez que depende de um acordo setorial não finalizado até o momento, conforme informação do SINIR (2018).

Como resultado geral, é possível evidenciar que muitas organizações já realizaram modificações nos produtos e processos visando reduzir o impacto no meio ambiente e estão participando do acordo setorial, principalmente através de suas entidades representativas, para definir questões práticas do sistema de logística reversa que será implantado no Brasil, como a questão do custo de coleta e transporte e as responsabilidades de cada parte (governo, indústrias, comércio, importadores e consumidores), por exemplo. Desta forma, o cenário atual das organizações pesquisadas parece favorável à implantação da logística reversa para os EEE no Rio Grande do Sul.

A contribuição deste trabalho foi apresentar a situação de indústrias de equipamentos eletroeletrônicos no RS, no ano de 2015, em relação ao atendimento dos requisitos da PNRS, do processo produtivo, dos produtos e informações prestadas aos consumidores. No futuro, seria interessante verificar se haverá evolução nos indicadores utilizados neste trabalho, após a finalização do acordo setorial, que parece ser o principal impeditivo para a implantação do sistema de logística reversa no setor. Também pode-se pesquisar formas de produção e desenvolvimento novos produtos eletroeletrônicos que utilizem matérias primas recicláveis e menos agressivas ao meio ambiente, que facilitem a desmontagem e o retorno dos componentes ao setor produtivo. 
Referências

ABINEE. ASSOCIAÇÃO BRASILEIRA DA INDÚSTRIA ELÉTRICA E ELETRÔNICA. Desempenho setorial no Rio Grande do Sul. 2011.

AGDI. AGÊNCIA GAÚCHA DE DESENVOLVIMENTO E PROMOÇÃO DO INVESTIMENTO. Dados do Programa Setorial: Eletroeletrônica, Automação e Telecomunicações. Disponível em: http://www.agdi.rs.gov.br/?model=conteudo\&menu=873. Acesso em: 10 out. 2015.

BRAGA, B.; HESPANHO, I.; CONEJO, J.G.L.; MIERZWA, J.C.; BARROS, M.T.L.; SPENCER, M.; PORTO, M.; NUCCI, N.; JULIANO, N.; EIGER, S. Introdução à Engenharia Ambiental. São Paulo: Pearson Prentice Hall, 2005.

BRASIL. Lei 12.305. Política Nacional de Resíduos Sólidos. 2010.

BRESCANSIN, A.; RUIZ, M. S.; GABRIEL, M. L. D. S.; SILVA, J. L. Restrição ao uso de substâncias perigosas (RoHS) no segmento de computadores pessoais: análise da estratégia de adoção pelos fabricantes estabelecidos no Brasil. GEPROS. Gestão da Produção, Operações e Sistemas, v.10, n. 3, p. 35-51, 2015.

BUENO, Eduardo. Indústria de ponta: uma história da industrialização do Rio Grande do Sul. Porto Alegre: Buenas Ideias, 2009.

ELETROS. ASSOCIAÇÃO NACIONAL DE FABRICANTES DE PRODUTOS ELETROELETRÔNICOS. Quem somos. Disponível em: http://eletros.org.br/portal.php/quem-somos. Acesso em: 18 out. 2015.

EPA. ENVIRONMENTAL PROTECTION AGENCY. Dioxins and Furans. Disponível em: http://www3.epa.gov/epawaste/hazard/wastemin/minimize/factshts/dioxfura.pdf. Acesso em: 16 out. 2015.

CALEIRO, J. P. Indústria eletrônica local voltará a crescer e subir em ranking. 2017. Disponível em: https://exame.abril.com.br/economia/industria-eletronica-local-voltara-acrescer-e-subir-no-ranking/. Acesso em: 28 jun. 2018.

FIESP. Gerenciando a Escassez de Água na Indústria. Disponível em: http://hotsite.fiesp.com.br/aguanamedida/publicacao/folder-agua-industria.pdf. Acesso em: 19 out. 2015.

FIPECAFI. Fundação Instituto de Pesquisa Contábeis, Atuariais e Financeiras. Análise Multivariada: para cursos de Administração, Ciências Contábeis e Economia. São Paulo: Atlas, 2007.

GREENPEACE. Green Gadgets. Disponível em: http://www.greenpeace.org/international/ en/campaigns/detox/electronics/Guide-to-Greener-Electronics/Green-Gadgets/. Acesso em 26 out. 2015. 
Guide to Greener Electronics. 2012. Disponível em: http://www.greenpeace.org/international/en/Guide-to-Greener-Electronics/18th-Edition/. Acesso em 26 out. 2015.

Guide to Greener Electronics. 2017. Disponível em: https://www.greenpeace.org/archive-international/en/campaigns/detox/electronics/Guide-toGreener-Electronics/. Acesso em 26 out. 2015.

HAIR, Jr., J.F.; ANDERSON, R.E.; TATHAN, R.L.; BLACK, W.C. Análise multivariada de dados. 5. Ed. Porto Alegre: Bookman, 2005.

HAUSER, G.; ZEN, A. C.; SELAO, D. C.; GARCIA, P. L. A Indústria Eletrônica no Brasil e na China: Um Estudo Comparativo e a Análise das Políticas Públicas de Estímulo a Capacidade Tecnológica do Setor. J. Technol. Manag. Innov., v. 2, n. 3., p. 85-96, 2007.

KAUARK, F.; MANHÃES, F.C.; MEDEIROS, C.H. Metodologia da pesquisa: guia prático. Itabuna: Via Litterarum, 2010.

KOBAL, M. A. B.; SANTOS, S. M.; LÁZARO, J. C.; CABRAL, A.C.A. O setor produtivo de eletroeletrônicos e a logística reversa de seus produtos pós-consumo. Produto \& Produção, v. 15, n.2, p. 46-65, jun. 2014.

LAU, J. H.; WONG, C.P.; LEE, N.C.; LEE, S.W.R. Electronics Manufacturing: With LeadFree, Halogen-Free, and Conductive-Adhesive Materials. New York: McGraw-Hill Professional, 2003.

LEITE, P.R. Logística Reversa: meio ambiente e competitividade. São Paulo: Pearson Prentice Hall, 2009.

MALHOTRA, N. Pesquisa de Marketing: Foco na Decisão. 3 ed. São Paulo: Pearson Prentice Hall, 2011.

MMA. Ministério do Meio Ambiente. Logística Reversa - Sistemas Implantados. Disponível em: http://www.mma.gov.br/cidades-sustentaveis/residuos-perigosos/logisticareversa/sistemas-implantados. Acesso em: 15 out. 2015(a).

BRA/08/G32: estabelecimento da gestão de resíduos de PCB e sistema de disposição. Disponível em: http://www.mma.gov.br/comunicacao/item/43. Acesso em: 15 out. 2015(b).

RoHS Brasileira. Disponível em: http://www.mma.gov.br/segurancaquimica/gestao-das-substancias-quimicas/rohs-brasileira. Acesso em 06 jul. 2018.

NASCIMENTO, L. F.; LEMOS, A. D. C.; MELlO, M. C. A. Gestão Socioambiental Estratégica. Porto Alegre: Bookmann, 2008. 
NNOROM, I.C.; OSIBANJO, O. Overview of electronic waste (e-waste) management practices and legislations, and their poor application in the developing countries. Resources, Conservation \& Recycling. v. 52, p. 843-858. 2008.

OLIVEIRA, L.H.; CHIESI, F.K.; BARBIERI, J.C. Manufatura reversa e gerenciamento de resíduos eletroeletrônicos: o Caso da Oxil. In: ENCONTRO NACIONAL DOS CURSOS DE GRADUAÇÃO EM ADMINISTRAÇÃO, 23, 2012, Bento Gonçalves. Anais... Bento Gonçalves: ENANGRAD, 2012.

PARLAMENTO EUROPEU. Directive 2011/65/EU of the European Parliament and of the Council of 8 June 2011 on the restriction of the use of certain hazardous substances in electrical and electronic equipment. Disponível em: http://eur-lex.europa.eu/legalcontent/EN/TXT/?uri=CELEX:02011L0065-20150624. Acesso em: 18 out. 2015(a).

PARLAMENTO EUROPEU. Directive 2012/19/EU of the European Parliament and of the Council of 4 July 2012 on waste electrical and electronic equipment (WEEE) Disponível em: http://eur-lex.europa.eu/legal-content/EN/TXT/?uri= CELEX:32012L0019. Acesso em: 18 out. 2015(b).

PATÓN-ROMERO, J. D.; BALDASSARRE, M. T.; PIATTINI, M.; GUZMÁN, I. G. R. A Governance and Management Framework for Green IT. Sustainability, v.9, n.1761, 2017.

RUIZ, M.S.; CORTES, P. L.; TEIXEIRA, C.E.; AGUIAR, A.O. Diretiva RoHS: nova barreira técnica ambiental às exportações brasileiras? In: ENCONTRO INTERNACIONAL SOBRE GESTÃO EMPRESARIAL E MEIO AMBIENTE, 13, 2011, São Paulo. Anais...São Paulo: ENGEMA, 2011.

SEBRAE. Serviço Brasileiro de Apoio às Micro e Pequenas Organizações. Anuário do trabalho. 2014. Disponível em: http://www.sebrae.com.br/Sebrae/Portal\%20Sebrae/ Anexos/Anuario-do\%20trabalho-na\%20micro-e-pequena\%20empresa-2014.pdf. Acesso em 26 out. 2015.

SIEGEL, S. Estatística não-paramétrica para ciências do comportamento. 2 ed. Porto Alegre: Artmed, 2006.

SINIR. Logística Reversa. Disponível em: http://sinir.gov.br/ web/guest/logistica-reversa. Acesso em: 18 jun. 2018.

TUA SAUDE. Principais sintomas de contaminação por metais pesados. Disponível em: http://www.tuasaude.com/principais-sintomas-de-contaminacao-por-metais-pesados/_Acesso em: 20 out. 2015.

WANG, H. F.; GUPTA, S. M. Green Suply Chain Management Product Life Cycle Approach. Columbus: McGrawHill, 2001. 